\title{
e-Migrinter
}

$21 \mid 2020$

Famille et migrations

\section{Mémoires en exil}

\section{Antonio Ramos Ramírez}

\section{OpenEdition}

Journals

Édition électronique

URL : https://journals.openedition.org/e-migrinter/2396

DOI : 10.4000/e-migrinter.2396

ISSN : 1961-9685

\section{Éditeur}

UMR 7301 - Migrinter

Référence électronique

Antonio Ramos Ramírez, « Mémoires en exil », e-Migrinter [En ligne], 21 | 2020, mis en ligne le 15 janvier 2021, consulté le 20 mai 2021. URL : http://journals.openedition.org/e-migrinter/2396 ; DOI : https://doi.org/10.4000/e-migrinter.2396

Ce document a été généré automatiquement le 20 mai 2021.

Tous droits réservés 


\title{
Mémoires en exil
}

\author{
Antonio Ramos Ramírez
}

Ce média ne peut être affiché ici. Veuillez vous reporter à l'édition en ligne http:// journals.openedition.org/e-migrinter/2396

2 Comme le spectateur pourra le vérifier, Mémoires en exil n'est pas un documentaire audiovisuel de facture professionnelle, mais un travail universitaire qui cherchait à s'interroger sur la mémoire (et les mémoires) de quelques enfants espagnols exilés en France et en URSS, il y a plus de quatre-vingts ans.

3 L'origine de cette effort collectif, de nature plus pédagogique que scientifique ou cinématographique, se trouve dans l'invitation que l'Institut de Relations Internationales de Moscou fit à Immaculada Fàbregas, directrice du département d'études ibériques et ibéro-américaines de l'UBS à ce moment-là, pour participer au VII Congrès scientifique international d'hispanistes « Homo loquens en el espacio lingüístico iberoamericano : investigación y enseñaza ", célébré du 21-23 avril 2016. Dans ce cadre, nous devions jouer la pièce de théâtre préparée au cours de l'année mais, l'enjeux de trouver des sources de financement permettant nous rendre à Moscou, nous invita à ouvrir une réflexion sur la problématique à traiter, dans le but de présenter un projet qui aurait des retombées pour la communauté universitaire de Lorient.

D'un point de vue pédagogique, la réalisation de Mémoires en exil fut pertinente parce que l'élaboration du projet (ainsi que les phases de production, tournage, édition, montage sous-titrage et diffusion) contribua à la formation académique de ces étudiants, en développant les compétences en langue et civilisation espagnole qui étaient nécessaires.

5 L'équipe de travail était constituée par une étudiante et un étudiant en master et trois étudiantes en licence LLCER-Espagnol'1 , qui faisaient partie de l'association Los Bufones, responsables aussi de la troupe de théâtre en langue espagnole. Avec mon accompagnement comme encadrant pédagogique du projet, et grâce au soutien financier de l'UBS, la Mairie de Lorient et le CROUS de Bretagne-Rennes, Los Bufones ont 
réussi à organiser un séjour d'une semaine, ce qui nous permit de rencontrer les niños de Rusia au centre espagnol de Moscou.

6 L'ensemble de cinq entretiens qui composent le documentaire (trois à Moscou et deux en Bretagne) essaie de mettre en lumière des histoires de vie marquées par la séparation violente de leurs racines. Dans ce sens, chaque témoignage réfléchit sur l'importance de la famille, comme une absence qui traverse les récits de cette tragédie aussi personnelle que collective.

7 Mémoires en exil a déjà été projeté dans le cadre de différents colloques scientifiques et lors de rencontres avec des associations œuvrant pour la récupération de la mémoire historique en Espagne. En participant à ce dossier, nous espérons pouvoir contribuer à partager la mémoire d'un passé qui est toujours très présent.

\section{NOTES}

1. Il s'agit de: Ginés Cervantes López, Clara Díez Márquez, Orlane Truffe, Marion Huiban et Gwenola Huiban.

\section{RÉSUMÉS}

À l'occasion du 80ème anniversaire du coup d'État contre la République espagnole, qui déclencha la guerre d'Espagne entre 1936-1939, un groupe d'étudiants de l'Université Bretagne Sud à Lorient (UBS) eut l'opportunité de mener à bien un projet collectif autour de cette évènement majeur de l'histoire européenne contemporaine.

\section{INDEX}

Mots-clés : histoire, guerre civile, exil, témoignage, documentaire Index géographique : Espagne, France

\section{AUTEUR}

\section{ANTONIO RAMOS RAMÍREZ}

Maître de conférences, Université Paris 8

antonio.ramos-ramirez@univ-paris8.fr 